\title{
Minimisation of Surface Mining Costs using Artificial Neural Network
}

\author{
P. Y. Dhekne ${ }^{1}$, Nawal Kishore ${ }^{2}$, and Romil Mishra ${ }^{1}$ \\ ${ }^{1}$ Faculty, Department of Mining Engineering, National Institute of Technology, Raipur, India and \\ ${ }^{2}$ Faculty, Department of Mining Engineering, IIT-BHU Varansi, India
}

\begin{abstract}
Costs of surface mining unit operations are controlled by rock fragmentation distribution. The costs can be reduced if the muck pile does not contain oversize fragments which require crushing and grinding. The oversize fragments can be reduced by adjusting the surface mine blast design so that their number in the muck pile is minimum. This paper explains the application of the Artificial Neural Network (ANN) for the minimisation of oversize fragments so that overall cost is minimum. It was observed that the trained neural network model estimated the boulder count with sufficient accuracy and it provides a feasible choice to the field engineers to optimize the blast design so that the boulder-count is the minimum and subsequently the improving the efficiency of downstream operations and their costs
\end{abstract}

Keywords: Artificial neural network, Blasting, Rock fragmentation, Boulder count.

\section{Introduction}

Production of mineral from a mine involves a number of unit operations downstream to drilling and blasting. Drilling and blasting claim around $20 \%$ share of the total operating costs, the efficiency of other downstream operations and ultimately their costs - which account for almost $80 \%$ of the total operating cost, depend largely on the fragmentation distribution resulting from blasting. This requires the breakage in such a way that the oversize fragments are minimum. Thus, minimisation of oversize fragments (boulder) is always one of the objectives in any production blasting. The objective can be achieved by improving the efficiency of drilling and blasting. Rock fragmentation is a complex phenomenon and it depends upon many factors. These factors can be grouped in four different categories: rock geotechnical parameters such as density, hardness, compressibility; explosive parameters such as density, velocity of detonation; technical parameters such as delay interval, primer strength and location and geometrical parameters such as burden, spacing, and stemming [1]. Concept of Artificial Neural Network (ANN) has been applied to model the fragmentation [2]-[12] etc. ANN is suitable in such a case because a large number of affecting variables and their complicated mutual dependence is not reflected in the output of empirical modeling. Fragment size or as the sieve analysis of the muckpile can be obtained from the developed ANN based fragmentation models. Mining engineers are interested in knowing the boulder count so that they can plan the secondary breakage operations to reduce the downstream operation costs. Therefore an ANN model has been developed to predict the boulder count. The data sets required for the development of the model have been generated from the Limestone quarries.

\section{Description Of The Sites}

The ANN model described in this paper has been developed from the blast records generated from Baikunth, Hirmi, Sonadih and Rawan Limestone quarries. The quarries are situated in Raipur district of Chhattisgarh province of India and are located within a radius of $20 \mathrm{~km}$. The geotechnical properties of the deposits are summarized in Table 1. 
TABLE 1: Geotechnical Properties of Limestone Deposits (*Mean values).

\begin{tabular}{|c|c|c|c|c|c|c|}
\hline $\begin{array}{c}\text { Name of } \\
\text { the } \\
\text { Quarry }\end{array}$ & $\begin{array}{c}\text { Uniaxial* } \\
\text { Compressive } \\
\text { strength }(\mathrm{M} \mathrm{Pa})\end{array}$ & $\begin{array}{c}\text { Density* } \\
(\mathrm{g} / \mathrm{cc})\end{array}$ & $\begin{array}{c}\text { Young's* } \\
\text { Modulus } \\
(\mathrm{G} \mathrm{Pa})\end{array}$ & $\begin{array}{c}\text { Porosity* } \\
(\%)\end{array}$ & $\begin{array}{c}\text { Vertical * } \\
\text { Spacing } \\
\text { between } \\
\text { Joints }(\mathrm{m})\end{array}$ & $\begin{array}{c}\text { Horizontal* } \\
\text { Spacing } \\
\text { between Joints } \\
(\mathrm{m})\end{array}$ \\
\hline Baikunth & 38 & 2.25 & 46 & 6 & 1.0 & 0.6 \\
\hline Rawan & 43 & 2.38 & 49 & 5 & 1.5 & 0.9 \\
\hline Sonadih & 45 & 2.35 & 48 & 7 & 1.4 & 0.8 \\
\hline Hirmi & 44 & 2.40 & 50 & 5 & 2.0 & 1.0 \\
\hline
\end{tabular}

Thus, the deposits of the four quarries have a similar geotechnical set-up and are competent. The holes are drilled in two to three rows on staggered pattern. Row to row delay with cord relays is maintained at $50 \mathrm{~ms}$ whereas the delay with shock tube initiation is $42 \mathrm{~ms}$. Blasts are carried out either with Ammonium Nitrate- Fuel Oil mixture or with Site-Mixed Emulsion Explosive. The other details of blast practice are given in Table 2.

TABLE 2: Blast Practice Details

\begin{tabular}{|c|c|c|c|c|c|c|c|c|}
\hline $\begin{array}{l}\text { Name of } \\
\text { the } \\
\text { Quarry }\end{array}$ & $\begin{array}{l}\text { Dia } \\
(\mathrm{mm})\end{array}$ & $\begin{array}{l}\text { Spacing } \\
(\mathrm{m})\end{array}$ & $\begin{array}{l}\text { Burden } \\
(\mathrm{m})\end{array}$ & $\begin{array}{l}\text { Depth } \\
\text { (m) }\end{array}$ & $\begin{array}{l}\text { Explosive } \\
\text { type }\end{array}$ & Primer & $\begin{array}{c}\text { Initiation } \\
\text { method }\end{array}$ & $\begin{array}{c}\text { Secondary } \\
\text { breakage } \\
\text { method }\end{array}$ \\
\hline \multirow[t]{2}{*}{ Baikunth } & 11 & 5 & 3.0 & \multirow[t]{2}{*}{8.0} & $\mathrm{O}$ & $\begin{array}{c}\text { Cartridge } \\
\text { booster/Cast } \\
\text { booster }\end{array}$ & $\begin{array}{l}\text { Cord } \\
\text { relays }\end{array}$ & \multirow{2}{*}{$\begin{array}{c}\text { Secondary } \\
\text { blasting/ } \\
\text { Rock } \\
\text { breaker }\end{array}$} \\
\hline & 152 & $6.5-7.0$ & $4.5-5.0$ & & SME & Cast booster & & \\
\hline Rawan & 152 & 7.0 & 4.0 & 8.0 & SME & Cast booster & $\begin{array}{l}\text { Shock } \\
\text { tubes }\end{array}$ & $\begin{array}{c}\text { Rock } \\
\text { breaker }\end{array}$ \\
\hline Sonadih & 100 & 4.0 & 3.0 & 90 & SMF & Cast booster & $\begin{array}{l}\text { Shock } \\
\text { tubes }\end{array}$ & $\begin{array}{c}\text { Rock } \\
\text { breaker }\end{array}$ \\
\hline \multirow{2}{*}{ Hirmi } & 115 & 4.0 & 6.0 & \multirow{2}{*}{8.0} & ANFO & \multirow{2}{*}{$\begin{array}{l}\text { Cartridge } \\
\text { booster/Cast } \\
\text { booster }\end{array}$} & $\begin{array}{l}\text { Cord } \\
\text { relays }\end{array}$ & \multirow{2}{*}{$\begin{array}{c}\text { Rock } \\
\text { breaker }\end{array}$} \\
\hline & 152 & 7.0 & 5.0 & & SME & & $\begin{array}{l}\text { Shock } \\
\text { tubes }\end{array}$ & \\
\hline
\end{tabular}

\section{Data Collection}

Research [13] indicates that the following factors affect the fragmentation in competent rocks:

a) Explosive energy per unit volume of rock mass, i.e. specific charge

b) Explosive distribution within the rock mass

c) Type of explosive

d) Delay timing

e) Joint system and its orientation with respect to blast direction.

The specific charge is logically correlated with the number of holes/row, number of rows, average depth, average spacing, average burden and total quantity of explosive fired in one round. On the similar considerations the type of the explosive replaces the $\mathrm{VoD}$ and the density of the explosive. The explosive distribution is represented by the diameter of the blast hole and the stemming height. The geotechnical parameters and the delay practice were similar in the referred mines hence they have not been considered as an input variable. The input variables are therefore the number of holes per row, number of rows, average spacing, average burden, average depth, diameter, average stemming, type of the explosive and the total charge. The target variable is the boulder (size $>1 \mathrm{~m}$ ) count as the maximum feed size of the crushers of the quarries is $1 \mathrm{~m}$. Three hundred blasts have been monitored to generate the records. Out of these, 191 records were used for training, 77 records for 
validation and 32 for testing of the ANN model. The Range of the data used for the development of the models is presented in Table 3.

TABLE 3: Range Of The Data Used For The Development Of Models

\begin{tabular}{|c|c|c|c|c|}
\hline \multirow{2}{*}{ Input Variables } & \multicolumn{4}{|c|}{ Value } \\
\cline { 2 - 5 } & Minimum & Maximum & Mean & $\begin{array}{c}\text { Standard } \\
\text { Deviation }\end{array}$ \\
\hline Diameter, mm $(D)$ & 100 & 152 & \multicolumn{2}{|c|}{ Not Applicable } \\
\hline Average burden, $\mathrm{m}(B)$ & 2.80 & 4.65 & 3.73 & 0.61 \\
\hline Average spacing, $\mathrm{m}(S)$ & 3.70 & 6.80 & 4.89 & 0.78 \\
\hline Average depth, $\mathrm{m}(H)$ & 7.00 & 9.75 & 8.66 & 0.61 \\
\hline Average stemming, $\mathrm{m}(T)$ & 2.60 & 4.30 & 3.33 & 0.39 \\
\hline Number of holes/row $(N)$ & 9 & 57 & 25 & 8.13 \\
\hline Number of rows $(n)$ & 2 & 3 & Not Applicable \\
\hline Type of the explosive & \multicolumn{5}{|c|}{ Value } \\
\hline Quantity of explosive fired per round, \\
kg $(Q)$
\end{tabular}

\section{ANN Model}

The ANN model described in this paper was developed using the syntax available in ANN tool box of MATLAB. A back-propagation neural network was selected due to its simplicity and uniform approximation of any continuous function. The number of neurons in the input layer was nine and the number of neurons in the output layer was one. Levenberg-Marquardt (LM) algorithm is used for training the network because it has good generalization ability and has the capability of providing good predictions. Generally, Log-Sigmoid ((Logsig), Hyperbolic tangent Sigmoid (Tansig), Positive Linear (Poslin) and Linear (Purelin) transfer functions are used in back propagation neural network (BPNN) [10]. The network was optimised for the number of hidden layers and type of the transfer function. As a result of optimization, a BPNN model (Fig 1) with one hidden layer with two neurons in it, Levenberg-Marquardt as training function and purelin function as transfer function is finalized.

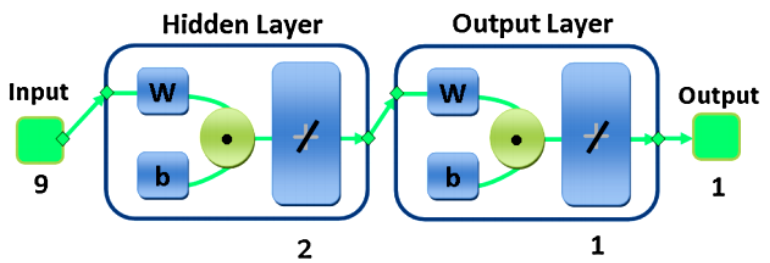

Fig 1. Developed Artificial Neural Network

152 and $100 \mathrm{~mm}$ diameter holes and the predictions are compared with target variables of these 32 records. The capability of the neural network is evident from Table 4 and Fig 2 and 3. 
TABLE 4: Estimation Results Of Boulder Count By Ann Model

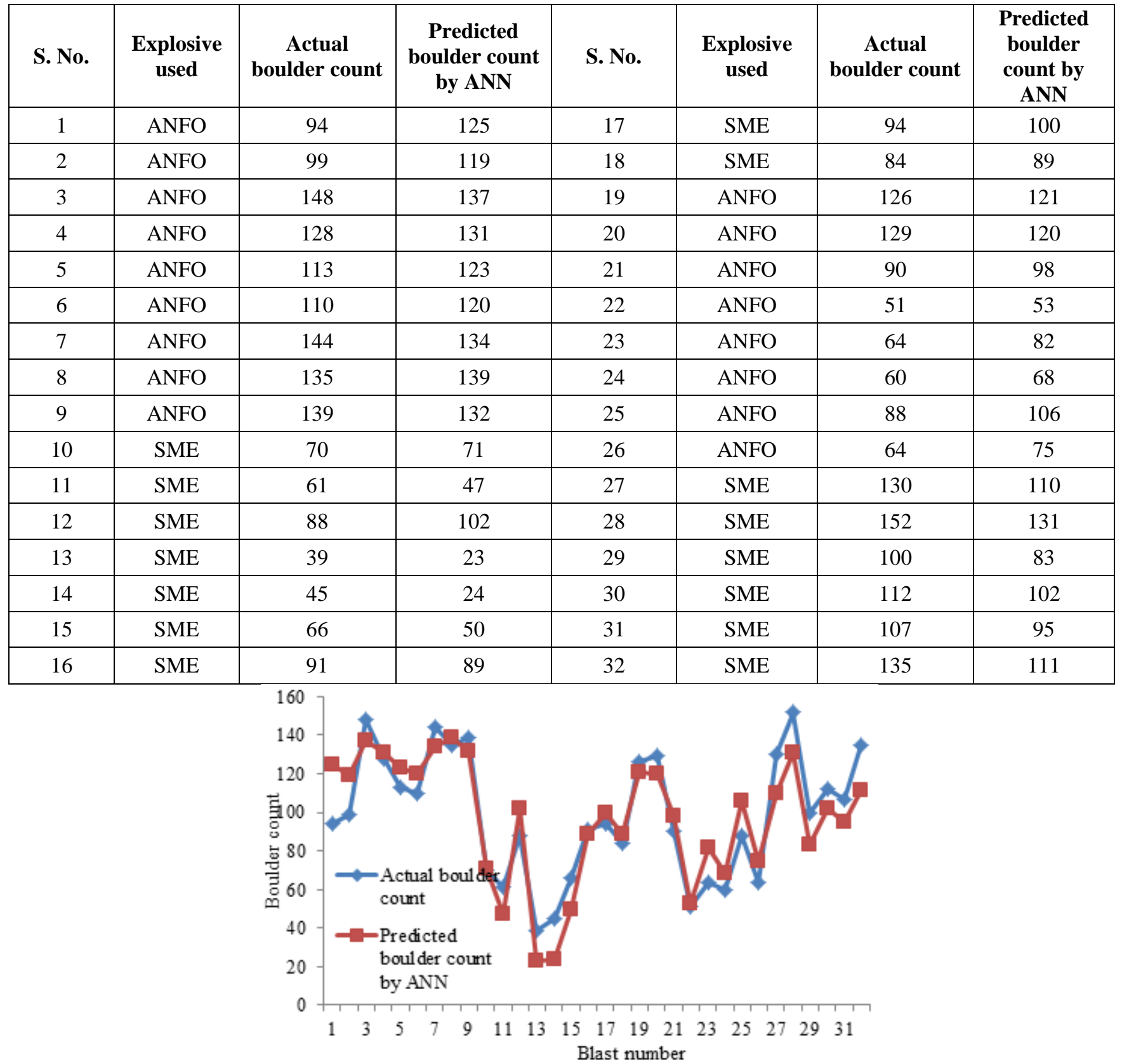

Fig 2 Predictive ability of ANN model

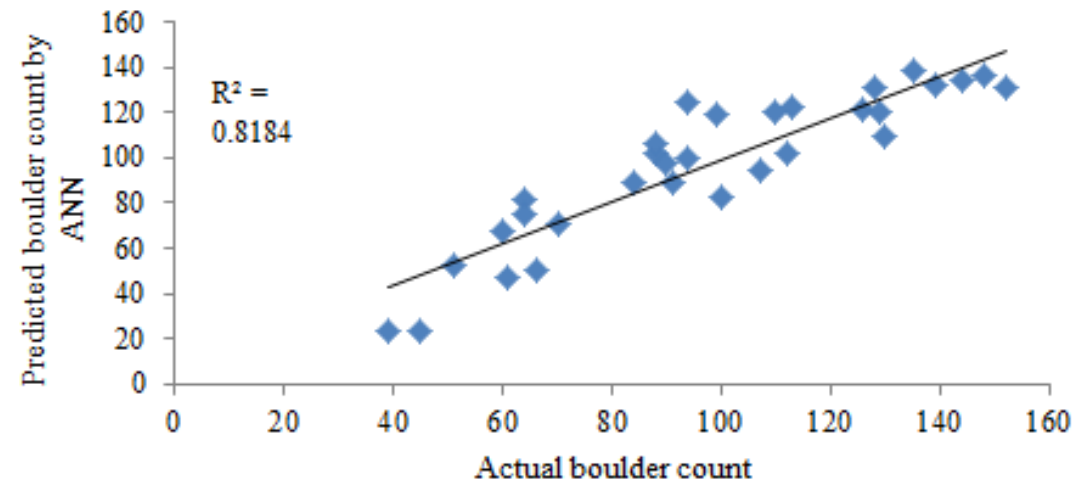

Fig. 3. Scatter obtained between the actual boulder count and the predicted boulder count by ANN. 


\section{Conclusion}

Rock blasting is a complex operation wherein the output depends upon a number of uncontrollable parameters. Therefore an accuracy of more than $80 \%$ in the predictions of boulder count is considered to be sufficient. It is observed that the correlation coefficient between the actual boulder count and predicted boulder count by ANN is more than 0.9; which can be considered as satisfactory. Thus, the artificial neural network seems to be a good option to predict boulder count. Different blast designs can be assessed for the boulder count. The design yielding minimum boulders can be considered as the best choice which can ultimately lead to minimum cost.

\section{References}

[1] A. Bahrami, M. Monjezi, K. Goshtasbi, and A. Ghazvinian, "Prediction of rock fragmentation due to blasting using Artificial Neural Network”, Engineering with Computers, Vol 27, pp.177-181, 2011.

[2] E. Ebrahimi, M. Monjezi, M.R Khalesi, and D.J. Armaghani, "Prediction and optimization of backbreak and rock fragmentation using an Artificial Neural Network and Bee Colony Algorithm", Bulletin of Engineering geo and Environ, DOI 10,1007/s10064-015-0720-2,2015.

[3] I. Enayatollahi, B. A. Aghajani, and A. Asa, "Comparison between Neural Network and multiple regression analysis to predict rock fragmentation in open pit mines", Technical Note, Rock Mechanics and Rock Engineering, Vol 47, pp 799-807, 2014.

[4] P.H.S.W Kulatilake, T. Hudaverdi, and W. Qiong, "New prediction models for mean particle size in rock blast fragmentation”, Geotech and Geological Engineering, Vol 30, pp 665-684, 2012.

[5] P.H.S.W.,Kulatilake, W. Qiong, T. Hudaverdi, and C. Kuzu, "Mean particle size prediction in rock blast fragmentation using Neural Networks", Engineering Geology, Vol 114 pp. 298-311, 2010.

[6] M.J. Moghadam, M.A.E. Farsangi, H. Mansouri, and H. Nezamabadi, "Muck -pile fragmentation prediction using Artificial Neural Networks", Journal of Mines, Metals and Fuels. Vol 54, pp 421-423, 2006.

[7] M. Monjezi, H. Amiri, A. Farrokhi, and K. Goshtasbi K, " Prediction of rock fragmentation due to blasting in Sarcheshmeh Copper mine using Artificial Neural Networks”, Geotech and Geological Engineering, Vol 28, pp 423430, 2010.

[8] M. Monjezi, H. A. Mohamadi, B. Barati, and M. Khandelwal, "Application of soft computing in predicting rock fragmentation to reduce environmental blasting side effects", Arab Journal of Geoscience, Vol 7, pp 505-511, 2014.

[9] K. Oraee, and B. Asi, "Prediction of rock fragmentation in open pit mines using Neural Network Analysis", Proceedings of $15^{\text {th }}$ International Symposium on Mine Planning and Equipment Selection (MPES), Torino, Italy, pp. 19-24, 2006.

[10] A. Sayadi, M. Monjezi., N. Talebi, and M. Khandelwal,“A comparative study on the application of various Artificial Neural Networks to simultaneous prediction of rock fragmentation and back break", Journal of Rock Mech and Geotech Engineering, Vol 5, pp 318-324, 2103.

[11] S. Z. Xiu, H. Dan, Z. Jian, and Z. Shu, "Combined ANN prediction model for rock fragmentation distribution due to blasting", Journal of Information and Computational Science, Vol 10, pp 3511-3518, $2013 .$.

[12] H. B. Zhu, and L. Wu, "Application of Gray correlation analysis and Artificial Neural Network in rock mass blasting", Journal of Coal Science and Engineering, Vol 11, pp 44-47, 2005.

[13] R.F. Chiappetta, "Choosing the right delay timing for the blasting application, optimization and maintaining field control", Proceedings of 8th High-Tech Seminar on State-of-the Art, Blasting Technology, Instrumentation and Explosives Applications, Allentown PA, USA, pp. 215-254, 1998. 